\title{
IDEOLOGÍA, PODER Y MANIPULACIÓN: \\ LA CULTURA MAPUCHE Y LOS INSTRUMENTOS \\ DISCURSIVOS DE LA PRENSA CHILENA
}

\author{
IDEOLOGY, POWER AND MANIPULATION: \\ THE MAPUCHE CULTURE AND THE DISCURSIVE \\ INSTRUMENTS OF THE CHILEAN PRESS
}

\author{
Julio Renato SÁEZ GALLARDO \\ Investigador \\ juliosaez2005@yahoo.es
}

Resumen: El objetivo central de esta investigación es entender cómo se construye en los diarios de mayor lectura en Chile la representación social de la cultura mapuche. Para ello, estudiaremos el aspecto cognitivo de la dimensión discursiva asociado al control que ejerce la prensa sobre las estructuras de la noticia y que incide fuertemente en la formación de modelos mentales en sus lectores sobre la alteridad étnica. La metodología que utilizaremos proviene del Análisis Crítico del Discurso (ACD) y su vinculación con la teoría del discurso periodístico; la Semiótica Visual de Kress y Van Leeuwen (1996) y la Semiótica greimasiana.

Palabras clave: Manipulación. Discurso. Racismo. Cultura mapuche. Prensa.

Abstract: The main goal of this research is to understand how the most 
read newspapers in Chile have established a social representation of the Mapuche culture. For this, the studied topic will be the cognitive aspect of the discursive dimension associated with the exercised control - by the press - over the structures of the news that strongly influences the formation of mental models in its readers about ethnic alterity. The methodology used will be the Critical Discourse Analysis (CDA) and its link with the theory of journalistic discourse; the Visual Semiotics of Kress and Van Leeuwen (1996) and the Greimasian Semiotics.

Key Words: Manipulation. Discourse. Racism. Mapuche Culture. Press.

\section{DISCURSO: MANIPULACIÓN, IDEOLOGÍA Y PODER}

En esta discusión teórica nos interesa dar algunas luces conceptuales de categorías crítico-analíticas que se imbrican con el discurso para comprender el abuso de poder que se instala en las rutinas periodísticas en contra de las minorías étnicas. No sin antes plantear que la noción de discurso presente en esta aproximación no dice relación con el discurso visto como reflejo de los acontecimientos sino discurso en tanto que interpretación y construcción de estos acontecimientos, de las relaciones sociales y de los sujetos. Vale decir: discurso como práctica tridimensional: como texto, como práctica discursiva y como práctica social (Fairclough: 1992). (las cursivas son nuestras).

Al ocuparnos de la manipulación no sólo nos centraremos en el nivel discursivo, sino también en ámbito social y cognitivo. Para van Dijk (2006) es un requisito fundamental examinar primero el contexto social para comprender y analizar el discurso manipulativo. Explícitamente, entiende por manipulación: 
[...] una práctica comunicativa e interaccional, en la cual el manipulador ejerce control sobre otras personas, generalmente en contra de su voluntad o en contra de sus intereses... es una categoría típica de un observador, por ejemplo, de un analista crítico y no necesariamente una categoría participante: pocos usuarios de una lengua llamarán manipulativos a sus discursos. La manipulación no sólo involucra poder, sino especificamente abuso depoder, es decir, dominación. En términos más especificos, pues, implica el ejercicio de una forma de influencia ilegítima por medio del discurso: los manipuladores hacen que los otros crean y hagan cosas que son favorables para el manipulador y perjudiciales para el manipulado. En un sentido semiótico de la manipulación, esta influencia ilegítima también puede ser ejercida con cuadros, fotos, películas u otros medios. De hecho, muchas formas contemporáneas de manipulación comunicativa, por ejemplo, por los medios de comunicación, son multimodales (Dijk, 2006: 51).

Concluye para este nivel que la manipulación como una forma de dominación o abuso de poder, como tal necesita ser definida en términos de grupos sociales o instituciones, y no a nivel individual de interacción personal. Así, la manipulación, socialmente hablando, es una forma discursiva de reproducción del poder de la élite que va en contra de los intereses de los grupos dominados y (re) produce la desigualdad social (Dijk, 2006).

En lo relativo a la dimensión cognitiva de la manipulación van Dijk (2006) explica cómo el procesamiento del discurso y la formación de modelos mentales y representaciones sociales son controlados por el discurso manipulativo. Plantea que manipular a la gente implica manipular sus mentes, es decir, sus conocimientos, opiniones e ideología que, a su vez, controlan sus acciones.

A nivel del discurso van Dijk (2006) se centra en las propiedades 
típicas del discurso que se usan al manipular las mentes de los receptores, tales como la presentación positiva de uno mismo y negativa de los otros, en todos los niveles del discurso y en un contexto que presenta las limitaciones típicas de las situaciones manipulativas: hablantes poderosos y receptores que carecen de recursos específicos, es decir, conocimiento para resistir la manipulación.

Para entender las relaciones entre el fenómeno del racismo, la ideología y los discursos relacionados con la cultura mapuche que podemos encontrar situados en la prensa escrita objeto de nuestra atención nos ocuparemos con van Dijk (1999) sobre el análisis ideológico del lenguaje y del discurso. Coincidimos con este autor que no hay ideologías sin lenguaje, enfoque que concibe a éste como uno de los vehículos por excelencia de la transmisión y reproducción de las distintas ideologías. Basado en el principio de la expresabilidad: todas las creencias, y en consecuencia también las ideologías, pueden ser expresadas o formuladas en lenguaje natural. Evidentemente que las ideologías no se expresan y reproducen solamente mediante el uso del lenguaje, sino también por otras prácticas sociales como la discriminación y la exclusión. De allí, nuestra opción por una teoría multidisciplinaria de la ideología, basada en la teoría combinada del conocimiento social, el discurso y la estructura de la sociedad (Dijk, 1999).

Teun van Dijk (1996) opta por situar su trabajo en un marco teórico más amplio y lo circunscribe en un análisis del discurso sociopolítico, en el que pretende:

[...] relacionar las estructuras del discurso con las estructuras sociales. De este modo, las propiedades y relaciones sociales de clase, género o etnicidad, por ejemplo, son asociadas sistemáticamente con unidades estructurales, niveles, o estrategias de habla y de las relaciones entre organizaciones sociales, instituciones, grupos, roles, situaciones, relaciones de poder o la toma de decisiones políticas, por una parte y las 
estructuras del discurso por la otra (Dijk, 1996: 15).

En la clásica aproximación sociopolítica al análisis ideológico, se considera a los usuarios del lenguaje como miembros de comunidades, grupos $\mathrm{u}$ organizaciones y se supone que hablan, escriben o comprenden desde una posición social específica. El análisis ideológico examina entonces, qué ideologías se encuentran particularmente asociadas con esa posición (Dijk, 1996).

Teun van Dijk define las ideologías "como sistemas que sustentan las cogniciones sociopolíticas de los grupos" (Dijk, 1996: 18). De este modo, las ideologías organizan las actitudes de los grupos sociales que consisten en opiniones generales estructuradas esquemáticamente acerca de temas sociales relevantes. Dependiendo de su posición, cada grupo seleccionará entre el repertorio de normas y valores sociales, propios de la cultura general; aquellos que realicen óptimamente sus fines e intereses, y se servirán de estos valores como los componentes que edifican sus ideologías de grupo (Dijk,1996).

La articulación entre discurso e ideología es importante para nuestro trabajo, ya que el análisis del discurso ideológico — específicamente las noticias objeto de nuestro análisis - presupone ciertos conocimientos en torno a estas relaciones. Sin embargo, asumimos con van Dijk (1999) que el propósito del análisis del discurso ideológico no es simplemente descubrir las ideologías subyacentes, sino articular sistemáticamente las estructuras del discurso con las estructuras de las ideologías. Desde ese punto de vista:

[...] la estrategia general de la autorrepresentación positiva y la presentación negativa del otro es un modo bien conocido para poner de relieve las estructuras ideológicas en el discurso. Lo contrario también puede ser válido en la descripción y atribución de acciones negativas, las cuales generalmente tenderán a ser desenfatizadas o desdibujadas para los grupos de pertinencia, 
ingroups (por ejemplo, mediante denegación, eufemismos, los implícitos y la de-topicalización) y enfatizada para los grupos ajenos (outgroups) (Dijk, 1996: 24).

Para tener un panorama comprensivo acerca del abuso de poder discursivo es necesario adentrarnos en una categoría crítica como es el poder. Desde su visión crítica Foucault relaciona el poder con el discurso. El poder es en esencia un fenómeno que atraviesa todos los escenarios en los que se despliega la vida humana. Su naturaleza última no puede ser aprehendida sino allí donde su intención está totalmente investida; en el interior de prácticas reales y efectivas y en relación directa con su blanco y campo de aplicación. Resulta lógico entonces no tomar el nivel macro como punto de partida para su análisis sino la multitud de actos que a diario son protagonizados por el individuo. No es algo que se precipita sobre el individuo y que se encuentra institucionalizado en formaciones sociales. No importa la legitimidad del mismo, si emana de los intereses de un grupo hegemónico o si es producto de la voluntad de la mayoría.

El planteamiento parte de que el poder se genera y materializa en una extensa gama de relaciones interpersonales desde las cuales se eleva hasta constituir estructuras impersonales. Foucault (1991) parte de la base de que existen dos esferas donde se consolidan las prácticas, cada una de ellas tiene sus propios mecanismos de legitimación, actúan como «centros» de poder y elaboran su discurso y su legitimación. Una de dichas esferas está constituida por la ciencia, la otra por el contrario está conformada por todos los demás elementos que pueden definirse como integrantes de la cultura. Lo ideológico, las diferenciaciones de género, las prácticas discriminatorias, las normas y los criterios de normalidad, están dentro de esta segunda esfera. Tanto una como otra con una referencia notoria a un tiempo y un espacio determinado. En medio de las dos esferas referidas queda una zona intermedia que es donde la cultura puede desprenderse de sus códigos primarios y mostrar lo consolidado como un "posible" entre otros. 
Utilizando la genealogía como sistema Foucault llega a la conclusión de que la instauración de la sociedad moderna supuso una transformación sustantiva en la consagración de nuevos instrumentos a través de los cuales canalizar el poder. De manera paralela se construyó un conjunto extenso de discursos que confirieron fuerza y capacidad de expandirse a esas nuevas formas de poder. Este ya no se basa como en el pasado en la fuerza y su legitimación religiosa. Dado que como afirma el hombre, en su actual dimensión es una creación reciente, el poder debe materializarse a través de diferentes formas de disciplinamiento.

\section{LA INVISIBILIZACIÓN DE LA CULTURA MAPUCHE COMO ESTRATEGIA RACISTA EN LA PRENSA CHILENA}

En las siguientes líneas nuestro interés crítico-analítico estará centrado en describir y analizar la estrategia de ocultamiento discursivo que articulan los diarios que son objeto de nuestro estudio al cubrir o más bien encubrir los hechos noticiosos que protagonizan los mapuche referente a la protesta contra el estado de Chile para que se reconsidere la aplicación de la Ley antiterrorista en su contra. Esta invisibilización que genera la prensa en lo referente a la multiculturalidad la concebimos como una forma de racismo que utiliza la elite simbólica para justificar la dominación y luego la exclusión de las fronteras de la nación bajo los argumentos de que los Otros mapuche no se avienen con la idea del progreso que se le atribuye al Nosotros, los blancos occidentales. Por lo demás:

[...] cuando los hombres oprimen a sus semejantes, el opresor siempre encuentra, en el carácter del dominado, la justificación plena de su opresión. Las alegaciones más comunes contra el oprimido son su ignorancia y su depravación, así como su impotencia para elevarse desde la decadencia hasta la civilización y respetabilidad. Frente a prácticas de explotación y dominación basadas en la discriminación, los explotadores 
pueden adoptar dos estrategias argumentativas: pueden negar la realidad social de la cual se aprovechan, o bien, racionalizar su funcionamiento de varias maneras como la conservadora que expresa que la gente consigue lo que merece y merece lo que le pasa (Taguieff, 2010: 21-22).

Los medios de comunicación son los encargados de reproducir las estructuras sociales al transmitir las creencias dominantes. Sin embargo, no lo hacen directamente, sino que construyen sus modelos mentales que se cristalizan en actitudes y prejuicios racistas. En este contexto son muy pertinentes los planteamientos de Bañón Hernández (1996, en Asturiano (2005) acerca del discurso prejuicioso etno-racial:

Desde el punto de vista de la simbologización en general, podríamos decir... que el discurso discriminatorio etno-racial se basa por un lado, en la invisibilización semiótica de la marginación y/o de los marginados; esa invisibilización puede presentársenos, primero como anulación y aniquilamiento simbólico, procesos que incluyen todas las estrategias semióticas $y$ lingüisticas al alcance de los marginadores para dar la impresión de que la marginación o los marginados simplemente no existen; y segundo, como atenuación, proceso mediante el cual se edulcora la marginación y se nos atenúa su gravedad. Y por otro, en la homogeneización simbólica, encarnada entre otras cosas, en una generalización argumental de los comportamientos negativos de individuos pertenecientes a grupos marginados: Todos son iguales y siempre hacen o dicen lo mismo (Asturiano, 2005: 5).

Desde de la óptica del Análisis Crítico del Discurso podemos sostener que las imágenes y las palabras generan un condicionamiento del discurso. Estas son una guía de percepción o reconocimiento cognoscitivo 
que pueden contribuir al fortalecimiento de estereotipos, en este caso racistas.

En lo que respecta a la invisibilización de la cultura mapuche acogemos los certeros planteamientos de Bañón Hernández (1996) y nos inclinamos a sostener que el discurso discriminatorio etno-racial que produce la prensa chilena en estudio se centra en una invisibilización que semiotiza a los mapuche por la vía mayoritaria de estrategias discursivas de anulación y aniquilamiento simbólico tanto a nivel lingüístico como en el plano de las imágenes que se utilizan para construir la alteridad. Sostenemos que la anulación de la cultura mapuche se produce en dos circunstancias específicas: en el tratamiento periodístico de la huelga de hambre mapuche y en la estrategia de cobertura noticiosa que se le brinda al rescate de los 33 mineros desde la mina San José por parte de la prensa nacional. Respecto del tratamiento periodístico de la huelga mapuche hemos visualizado - a la luz del análisis del corpus - cómo se invisibiliza la cultura mapuche por las estrategias semio-discursivas construidas para el aniquilamiento simbólico de la principal etnia de nuestro país, a saber: escaso tratamiento periodístico de la huelga mapuche en los diarios analizados; estrategias intertextuales que dan cuenta casi exclusivamente de la voz del gobierno y la iglesia. Además, los mapuche no son citados como fuentes en titulares como ocurre con esferas oficiales; otorgamiento de escasa centralidad y tamaño en las páginas del diario a las noticias referidas al tema mapuche; poca importancia de los aborígenes en las fotografías que ilustran los textos noticiosos; uso de lenguaje etnocentrista para la nominalización de los comuneros mapuche. Sólo adquieren notoriedad y visibilidad cuando se les construye ligados a estereotipos racistas como "violentos" e "intransigentes", tal como se plantea en Sáez (2015). Por lo demás, se les otorga importancia en circunstancias bien específicas: al ser retratados con personeros de las elites gubernamentales, políticas y religiosas. Sólo en estas circunstancias se les reviste de "legitimidad" y autorización social para visibilizar sus demandas. 


\subsection{El rescate de los mineros como estrategia discursiva de invisibilización de la cultura mapuche}

Para entender la hipervisibilización mediática que produjo el rescate de los 33 mineros chilenos y, consecuencialmente, el ocultamiento e invisibilización periodística de la huelga de hambre mapuche, proveeremos algunos datos de contexto para entender estos fenómenos. El derrumbe de la mina San José se produjo el jueves 5 de agosto de 2010, el que deja atrapados a 33 mineros a unos 720 metros de profundidad durante 70 días. El yacimiento, ubicado a $30 \mathrm{kms}$. al noroeste de la ciudad chilena de Copiapó, era explotado por la compañía San Esteban Primera S.A. Después de 17 días de trabajos para rescatarlos, los encontraron con vida, pero sin poder sacarlos definitivamente de las profundidades de la mina. Con sofisticadas máquinas perforadoras logran los rescatistas "romper fondo" a 623 metros de profundidad, lo que a la postre significó que el día 13 de octubre de 2010 se procediera a librar desde las profundidades de la mina San José a los 33 mineros chilenos que se encontraban atrapados luego que un derrumbe en la mina bloqueara la salida del pique. Según Francesc Puyol (2010), el impacto mediático mundial del rescate es el mayor de la historia reciente de Chile, superior al que generó el terremoto del 27 de febrero de 2010.

Este suceso noticioso que impactó al mundo se desarrolló en forma prácticamente paralela a la huelga de hambre mapuche: fueron 57 días en que estos dos eventos coinciden en su desarrollo en Chile. La huelga de hambre de los prisioneros mapuche se inicia el 12 de julio y culmina con un acuerdo entre el gobierno y los huelguistas el día 02 de octubre, al cumplirse 82 días de presión al gobierno de Sebastián Piñera. Los dos acontecimientos situaban como leiv motiv a la vida y su conservación: por un lado, en el norte del país 33 mineros luchaban para mantenerse vivos en extremas circunstancias a 720 metros de profundidad y, en el sur de Chile, 34 presos mapuche ponían en peligro sus propias vidas al someterse a una huelga de hambre para exigir ser juzgados por leyes 
comunes y no por la Ley Antiterrorista como lo pretendía el gobierno. No obstante, la coetaneidad y el valor de la vida humana en juego como elementos comunes a ambos hechos noticiosos, éstos no obtuvieron el mismo tratamiento periodístico por parte de la prensa escrita estudiada. Es por ello que abordaremos comparativamente cómo se semiotizan estos dos eventos mediante un análisis de las noticias que los abordan.

Para demostrar la asimetría comunicacional de estos eventos seguiremos a Kress y van Leeuwen (1996) y usaremos como categorías analíticas las tres maneras de composición de los textos multimodales para expresar los significados y captar la atención de los lectores referente al rescate de los 33 mineros y la huelga de hambre mapuche.

El valor de la información (information value): el lugar que se colocan los elementos, vale decir, de izquierda a derecha, de arriba abajo, del centro a los márgenes, etc. puede añadirles un valor determinado. Los titulares suelen aparecer en letra negrita y mayúscula en la parte superior de la página. Las imágenes y el texto escrito pueden aparecer a la derecha o a la izquierda, en la parte superior o inferior de la página. La parte izquierda, la de la información conocida, suele contener elementos de menor importancia que los que aparecen a la derecha ya que se asume que son conocidos por el lector; la parte derecha, la de la información nueva, es donde aparecen los elementos más importantes y donde el lector ha de concentrar su atención (Kress y van Leeuwen, 1996: 181).

-Prominencia (salience): los elementos pretenden captar la atención del lector, apareciendo en primer o segundo plano, el tamaño, los contrastes en los colores o la nitidez.

-Los marcos (framing): la presencia o ausencia de marcos que conectan o desconectan elementos significando que van o que no van unidos. Los marcos constituyen otra característica visual importante pues normalmente se emplean para destacar el texto escrito o la imagen. Tal y como señalan Kress y van Leeuwen (1996: 203), cuanto mayor sea el marco de un elemento, más se destaca que aparece como una unidad de información separada. 
Nuestro interés se centrará, entonces, en los siguientes elementos de la composición visual: la disposición o presentación de la página, los titulares, el color, la prominencia o rasgo más sobresaliente, los marcos que tiene la página y la fotografía o la imagen. La pregunta que pretendemos contestar es de qué manera "[...] se articulan los significados y el poder a través de las imágenes y el texto escrito que encontramos en los textos multimodales" (Martínez Lirola, 2006: 154) y de qué forma —según nosotros - se estructura el discurso que hiper-visibiliza a los mineros y, por ende, invisibiliza a los mapuches.

En efecto, la dispar cobertura de los medios elegidos en este estudio se grafica a nivel cuantitativo, por ejemplo, si consideramos el caso del Diario El Mercurio: este periódico en los 57 días que coinciden los eventos noticiosos en cuestión sólo 21 días cubre la huelga de hambre mapuche, en contraposición a los 48 días que le otorga atención mediática al rescate de los mineros. No obstante estas reveladoras cifras, lo que aquí nos mueve, desde un enfoque cualitativo, es entender cómo se excluye a los Otros-étnicos y se incluye al Nosotros mediante una estrategia discursiva ideológica de índole racista.

A continuación, nos centraremos en analizar comparativamente las noticias del rescate minero y el término de la huelga mapuche. Dada la revisión emprendida hemos constatado que el día 02 de octubre de 2010 , la prensa estudiada cubre los hechos noticiosos mencionados. Para el declarado propósito centraremos nuestra atención en cómo el diario $E l$ Mercurio construye desde sus rutinas periodísticas estos dos sucesos.

Como es posible apreciar la noticia que visualizamos a continuación -y sólo a modo de ejemplo ilustrativo - corresponde a la cobertura noticiosa que realiza el diario El Mercurio a las faenas preparatorias del rescate de los mineros en la ciudad de Copiapó (Chile). 


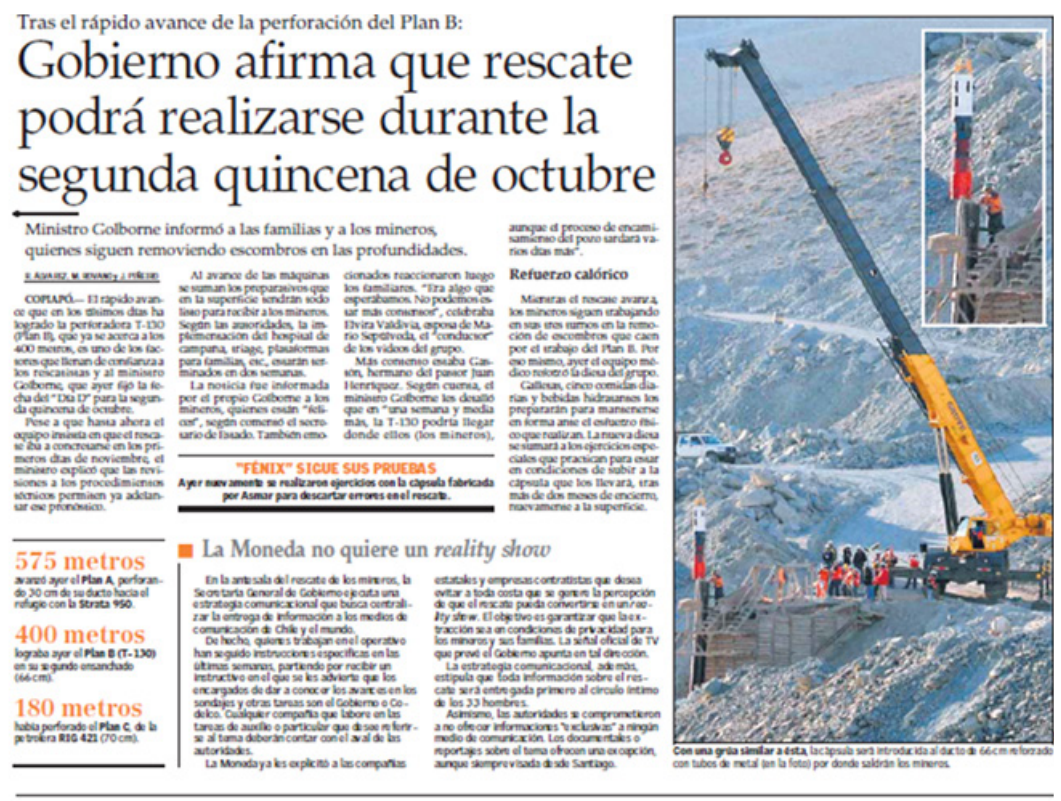

Figura 1. Noticia del diario El Mercurio sobre las faenas preparatorias del rescate de los mineros en la ciudad de Copiapó.

Respecto a la variable "valor de la información" es apreciable que se le atribuye un alto valor, dado que la noticia ocupa toda la extensión de la página y, tanto el texto verbal como el icónico compiten en notoriedad. En cuanto a la fotografía se encuentra posicionada en el lado derecho, es decir, constituye la información nueva, por tanto, adquiere mucha importancia para el lector. En ésta adquiere saliencia por contraste, saturación de colores y tamaño la grúa gigantesca, cuyo símil se ocupará para introducir la cápsula en el orificio taladrado en la piedra para extraer a los mineros desde las profundidades del socavón. En cambio, los trabajadores que la operan se ven diminutos (escasa saliencia), en razón de las colosales dimensiones de la máquina. En lo que respecta al encuadre (framing) apreciamos que posee escaso marco lo que comunica una mayor identificación del lector con el mundo significado.

En este esfuerzo contrastivo de develar la construcción periodística 
de la protesta étnica en relación al tratamiento periodístico del rescate minero nos centramos en el análisis de la cobertura que le otorgó el diario El Mercurio al término de la huelga de hambre mapuche, que se desarrolló por espacio de 82 días, en la zona sur de Chile. La referida noticia tiene un alto "valor informacional" (information value), dada la centralidad e importancia que se le asigna al cubrir toda la página del diario y, tanto el mensaje verbal como el icónico, poseen la misma extensión aproximadamente, índice que nos lleva a señalar que compiten en notoriedad, tal y como es posible advertir a continuación.

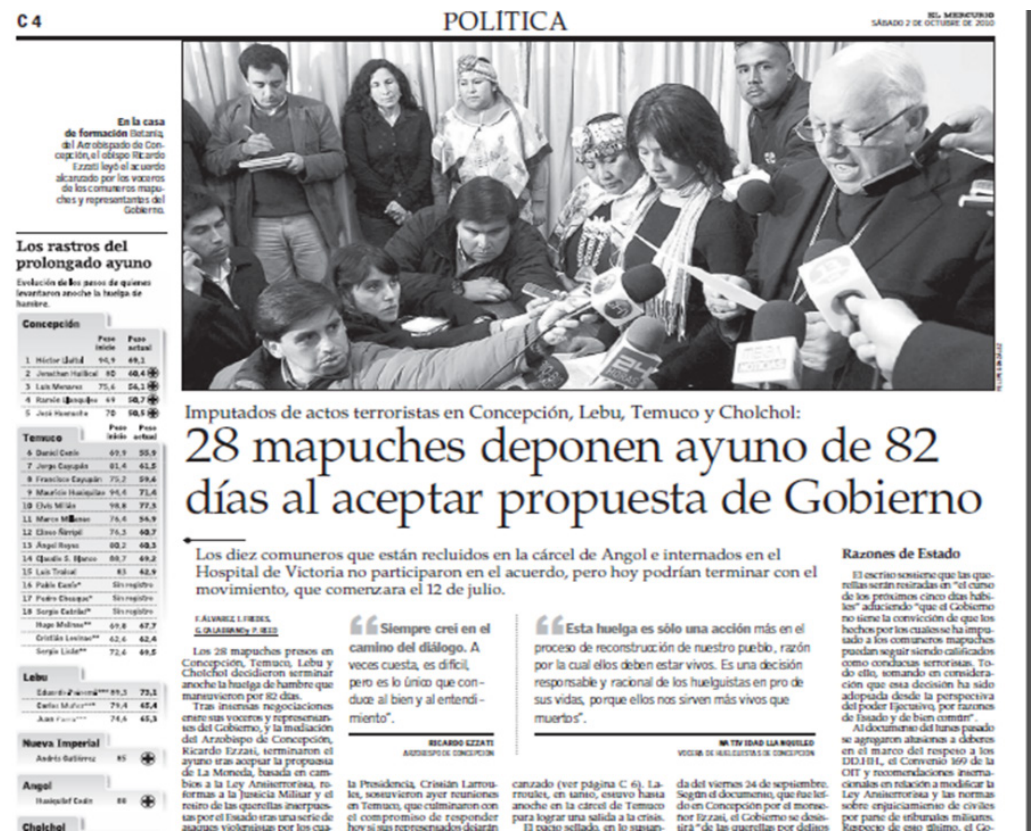

Figura 2. Noticia del diario El Mercurio sobre la huelga de hambre mapuche.

En cuanto a la fotografía podemos señalar que se encuentra posicionada en el extremo superior de la página, con mayor inclinación hacia el margen ideal nuevo, indicador que reviste a la noticia de mayor relevancia para los lectores. Al interior de ella apreciamos que la figura de monseñor Ezzati cobra mayor saliencia por encontrarse en primer plano 
y en el margen derecho (lo nuevo) y, además, por el contraste que ofrece el fondo claro con el traje negro del mediador del "conflicto" mapuche y por tener mayor agentividad al ofrecer una conferencia de prensa en la que comunica el acuerdo entre el gobierno y los comuneros mapuche, lo que a la postre significó el término de la medida de presión. En tanto, las voceras mapuche se ubican en segundos y terceros planos y no miran al lector (oferta), indicadores de escasa saliencia de las portavoces aborígenes en la composición visual. En lo que respecta al encuadre de la noticia es posible observar que posee un marco no tan pronunciado, indicativo que produce una tendencia de mayor identificación de parte del lector con el mundo narrado por la fotografía.

Tal como advierten Kress y van Leeuwen (1996) la estructura visual que hemos develado es ideológica en el sentido de que no puede corresponderse con lo que sostienen el productor (emisor), el consumidor (receptor) o el diseño. Lo importante, señalan estos autores, es que la información está presentada "como si" tuviera ese status para todos los lectores que la han leído dentro de esa estructura. En este sentido, la deconstrucción contrastiva que hemos emprendido nos permite aseverar que asistimos a una construcción ideológico-racista en función de la invisibilización del mundo mapuche que resulta de las rutinas profesionales de los medios estudiados.

Podemos concluir que - a pesar de que la referida noticia adquiere notoriedad - las voceras mapuche son construidas visualmente como entidades subalternas, supeditadas al representante de la elite religiosa, entidad que está autorizada social y simbólicamente para hablar en nombre de los aborígenes. Probablemente, esto último se deba a un resabio cultural de implantaciones legales de la Corona española que imperaban en el siglo XIX, relativas a las leyes de la República indígena que concebían al indio como un "incapaz relativo" y por lo cual necesitaba un tutor para intervenir en sociedad. 


\section{EL HACER CREER COMO DIMENSIÓN COGNITIVA PARA LA IDENTIFICACIÓN NEGATIVA DE LA CULTURA MAPUCHE EN LA PRENSA CHILENA}

En este apartado nos posicionaremos entre dos coordenadas epistemológicas para abordar el programa narrativo manipulador que se instaura en la prensa escrita de Chile en lo referente a la construcción de una representación social negativa de la cultura mapuche: por un lado, ocuparemos los postulados teóricos de la semiótica greimasiana $\mathrm{y}$, por otro, haremos un vínculo con los aportes de la teoría y análisis del discurso (periodístico) para el abordaje de la interpretación del texto periodístico, tal como lo sugieren Velázquez (2011) y Fontcuberta y Velázquez (1987) en su propuesta de análisis discursivo-semiótico.

Con el propósito de desprendernos de la carga semántica negativa que se le atribuye al concepto de manipulación cotidianamente, diremos que — desde la Teoría de la Manipulación de Greimas - narrativamente es hacer-hacer, lo cual supone un sujeto A del hacer que actúa sobre otro sujeto B de (otro) hacer. El primero modula y transforma "algo" en el segundo sujeto. El ejercicio del manipulador está marcado como uno de persuasión, en la narratividad ésta consiste en un hacer-creer: el destinador debe convencer al manipulado de la necesidad de lo solicitado, el manipulado debe quedar en situación de inevitable obediencia, y por lo tanto ejecutar lo que se le pide. El manipulado, como contraparte está compelido por un ejercicio de interpretación, su ejercicio epistémico consiste en decidir, en elegir creer o no-creer lo que le propone o pide el manipulador. En todo caso, es una elección forzada. Para aportar mayor claridad teórica diremos que éste:

[...] puede ejercer su hacer persuasivo apoyándose sobre la modalidad del poder: (tendiendo hacia) la dimensión pragmática, propondrá entonces al manipulado objeto pasivos (valores culturales) o negativos (amenazas); entre otros casos, 
persuadirá al destinatario mediante el saber: (tendiendo hacia) la dimensión cognoscitiva, le hará entonces saber lo que él piensa de su competencia modal en forma de juicios positivos o negativos. Asi pues, la persuasión según el poder caracteriza a la tentación (donde se propone un objeto de valor positivo) y a la intimidación (que ofrece un don negativo); la persuasión según el saber es propia de la provocación (con un juicio negativo: "Eres incapaz de...") y de la seducción (que manifiesta un juicio positivo). Por otro lado, El manipulado es impulsado a ejercer correlativamente un hacer interpretativo y a elegir necesariamente entre dos imágenes de su competencia — positiva en el caso de la seducción, negativa en la provocación-, si se trata de una manipulación según el saber; o bien entre dos objetos de valor —positivo, en la tentación; negativo en la intimidación -, si la manipulación se da sobre el poder (Greimas y Courtés, 1982: 252).

Diremos que la manipulación ejercida desde los medios de prensa escrita se inscribe en la esfera de los cognitivo, mediante su hacer saber y hacer creer a los lectores que la evaluación que ellos hacen de la realidad es la "verdad", por medio de la seducción como estrategia de su hacer manipulativo. Se desprende de lo que hemos planteado que toda construcción del imaginario social impulsada por los media es absolutamente parcial e interesada. No es posible la contextualización y focalización de un acontecimiento sin proyectar una dimensión interpretativa y valorativa. El ideal de la verdad y la objetividad, positivo en cuanto horizontes que animan la actividad configuradora del discurso informativo, se convierten — como muy acertadamente señala Vázquez Medel (1998) - en un discurso de ocultación cuando se pretenden una posesión propia frente a las carencias ajenas. Heinz von Foerster lo ha dicho con ejemplar precisión: la objetividad es la ilusión de que las observaciones pueden hacerse sin un observador (Cf. Watzlawick, comp., 1994: 19). 
En consecuencia, vemos que en el campo comunicativo del periodismo — dado nuestro interés por esta parcela disciplinaria- en el terreno de la interpretación de la realidad se instaura una lucha de operaciones cognoscitivas y de manipulaciones modales, donde la comunicación manipulatoria está regida por la modalidad factitiva (el hacer-hacer) que introduce un desequilibrio modal entre el manipulador y manipulado. Lo anterior, se hace extensible, por cierto, a todo sistema de organización social.

Aclarado teóricamente el proceso manipulador que se instala en la prensa para hacer creer al lector que la evaluación o interpretación de la realidad que se "construye" es el fiel reflejo de la realidad social, nos abocaremos a demostrar cómo la prensa escrita chilena utiliza una interpretación subjetiva — explícita o implícita — del hecho noticiable que lo constituye la huelga de hambre mapuche. Para lo cual, analizaremos a nivel de sumario de la noticia: Antetítulo (AT), Titular (T), Subtítulo (ST) y lead (L) y sus respectivas macroestructuras y veremos cómo aquella toma una particular posición mediante el estudio de la interpretación como categoría analítica superestructural. Para Velázquez y Fontcuberta (1987) la interpretación supone introducir elementos valorativos y de opinión acerca del hecho. Incluye la interpretación explícita o valoración y la interpretación implícita o intencionalidad. Se considera que el discurso de la noticia contiene siempre una intencionalidad que se evidencia tanto en su estructura interna (nivel semántico, orden de los topoi, etc.), como en el lugar que ocupa dentro de la unidad del periódico y de los elementos que la acompañan (fotografías, tamaño de las letras, número de columnas que ocupa).

\subsection{La interpretación explícita/implícita de la prensa chilena vinculada a juicios condenatorios sobre lo mapuche}

Veremos cómo la prensa escrita en estudio hace creer desde su rol político (Borrat, 1989) privilegiado su interpretación explícita acerca de la 
cultura mapuche: 1. (T) "Sumar menores a la huelga es una insensatez" (Ministro del Interior, Rodrigo Hinzpeter) (La Cuarta, 02/09/2010). Macroestructura: Declaración de rechazo al uso de menores en huelga. 2. (ST) "El Gobierno muy livianamente está haciendo cambios en las leyes que estaban vigentes. Nosotros luchamos y le exigimos al gobierno anterior que aplicara la Ley Antiterrorista" (José Villagrán. Presidente de los Transportistas de la Araucanía) (El Mercurio, 04/10/2010). Macroestructura: Crítica por cambios en la Ley Antiterrorista de parte de Presidente Transportistas. 3. (ST) “Asesina” y "traidora” son algunos de los insultos que familiares y simpatizantes de los 34 huelguistas, que ayer cumplieron 64 días sin comer, le gritaron a la ex vocera del gobierno de Bachelet" (La Cuarta, 12/09/2010). Macroestructura: Agresión verbal hacia ex vocera de Gobierno por familiares de huelguistas.

Se advierte en los ejemplos citados que la prensa objeto de análisis toma una postura explícita de rechazo ante el hecho noticiable de la huelga de hambre de los prisioneros mapuche. En razón de aquello, se alinea política e ideológicamente con la elite gubernamental para emitir juicios étnico-raciales condenatorios a la lucha reivindicativa del pueblo mapuche para no ser juzgados con leyes excepcionales como la Ley Antiterrorista. Bajo esta lógica etnocéntrica dominante los subyugados no pueden revelarse a las condiciones reificadas por el orden social y defendidas por el brazo cultural de la elite gobernante, en este caso, por la prensa. Esta le confiere un estatus veridictorio a su hacer creer su saber cognoscitivo a un lector que debe cooperar con la estrategia manipuladora, mediante la utilización de la intertextualidad como estrategia discursiva. Vale decir, se usa la cita directa de autoridades gubernamentales para dar fuerza y credibilidad a la interpretación de "la" realidad transmitida por los diarios La Cuarta y El Mercurio.

Finalmente, veremos a continuación, cómo se comunica la postura de la prensa respecto a la huelga de hambre mapuche por medio de la interpretación implícita del mencionado hecho noticiable: 4. (T) "Afectados por ataques mapuches critican acuerdo” (El Mercurio, 04/10/2010). 
Macroestructura: Crítica por acuerdo alcanzado de parte de afectados por ataques mapuche. 5. (T) "Gobierno acusa de intransigencia a mapuches en huelga tras primer día de negociación formal” (El Mercurio, 25/10/2010). Macroestructura: Acusación de intransigentes a mapuche por el Gobierno. 6. (ST) "Fondeada y con escolta tuvo que ser sacada de la cárcel de Temuco la Presi del PPD Carolina Tohá, para evitar que la furia mapuche se dejara caer sobre ella" (La Cuarta, 12/09/2010). Macroestructura: Protección a Presidenta del PPD para evitar agresión por mapuche.

En los ejemplos precedentes es posible advertir que la textualización que ocupa la prensa estudiada refleja - mediante implicaturas - una concepción de mundo (ideología) que interpreta y hace creer (e interpretar) al receptor como "verdadera" la otrificación desde la negación de los motivos profundos de la protesta indígena. Vale decir, que el destinador al centrarse en las consecuencias — según los medios escritos- disruptivas del orden social respecto de la huelga de hambre no hace más que invalidar lo que pudiera ser un reclamo justo en torno a una demanda étnica por ser tratados en igualdad de condiciones por los tribunales y a no ser discriminados social y políticamente al aplicárseles leyes excepcionales para castigar sus "supuestos" delitos por luchar en pos de la recuperación de sus tierras usurpadas por el estado de Chile. En el caso del pueblo mapuche, la intensidad de la negación material y práctica de su vidacultura, su re-construcción estereotipada y de otredad, su persecución política y encarcelamiento (como forma de captura, control y anulación) han sido parte de las formas que ha desarrollado el estado para (intentar) doblegar las reivindicaciones ancestrales del pueblo mapuche de territorio, autonomía y autodeterminación (Mella, 2007: 101-125).

\section{CONCLUSIONES}

Del análisis de las estrategias discursivas empleadas por los diarios La Cuarta y El Mercurio se desprende que todas ellas transmiten una imagen claramente negativa del mapuche y su cultura. Las estrategias 
analizadas dan cuenta de una representación social negativa del mapuche, invisibilizan sus aspectos positivos y, de paso, construyen una imagen positiva del Gobierno y la Iglesia. El discurso de la prensa ha dado forma entonces, al cuadrado ideológico, tan propio de los discursos ideológicos - en este caso de corte racista - en el que se re-produce una semiosis fronteriza entre los Otros y Nosotros. Este discurso racista detenta el poder de determinar las características identitarias del endogrupo y de perfilar los rasgos del mapuche otrificado, mediante un ataque discursivo que crea identidad por oposición e inscribe una relación entre los Otros y Nosotros en un plano de superioridad y dominación. Los procesos semióticos que configuran la frontera simbólica racista entre el exogrupo y el endogrupo - generados por la ideología dominante - se valen de un mecanismo semántico sinecdóquico tanto en lo visual como en lo lingüístico para generar una extensión o generalización simbólica de las características particulares de éstos y hacerlos ver como representativos de cada entidad, fenómeno que contribuye a la manipulación del imaginario social chileno. La representación social negativa que se construye del mapuche está vinculada con características atribuibles a su esencia más social y cultural que a rasgos fenotípicos. En virtud de ello, se le semiotiza como "violento", "intransigente", "ignorante", "de escaso valor social". Por ende, el racismo de la prensa se enmarca en la época actual en el denominado "nuevo racismo", en el entendido que se "racializa" al nativo en razón de sus diferencias culturales y no fenotípicas. Sin embargo, concluimos que ésta es una falaz macroestrategia de la prensa al recubrir el racismo fenotípico con un revestimiento de diferencialismo cultural, dado que aquel es muy combatido por las ideas democráticas e inclusivas. Por tanto, el verdadero racismo de los medios se configura en la lógica de otrificación más violenta y básica que pone el acento en el color de la piel (morena) y la condición social (desmedrada) como los parámetros de la discriminación del otromapuche, pero que se edulcora bajo un ropaje de diferencias culturales. La producción noticiosa en torno a la alteridad mapuche instala un programa narrativo-manipulativo desde la modalidad factitiva, en el ámbito 
cognitivo, para hacer creer por medio de la seducción que la interpretación de la realidad que efectúan los diarios analizados es "verdadera" y se ajusta a los criterios periodísticos de "objetividad". Es así como, mediante encuadres interpretativos prejuiciosos, se vehicula una visión sesgada y racista de la cultura-vida mapuche a las macroestructuras de la noticia del "conflicto" mapuche, las que reproducen y reflejan una interpretación subjetiva-implícita o explícita donde los medios escritos chilenos adoptan una postura de condena y rechazo a la protesta de los aborígenes. Esta postura ideológico-racista es instalada en los esquemas mentales de los lectores como "verdad" por medio de la fuerza ilocucionaria provista —en general - por la estrategia discursiva de la intertextualidad para producir la noticia que da tribuna en titulares, bajadas y lead a la voz de autoridades del gobierno y la iglesia y se omite la voz de los mapuche.

El rescate de los mineros y su hipervisibilidad periodística tiende a producir un cerco comunicacional y semiótico en detrimento de la cultura ancestral mapuche al producir, consecuencialmente, una invisibilización de la protesta indígena en contra del estado de Chile. Fenómeno que es correlacional, por un lado, a la cultura profesional racista de los periodistas de los medios abordados $\mathrm{y}$, por otro, a la visión sociocultural predominante que semiotiza la temática étnica como "conflicto" y, por ende, divide a los que están dentro y fuera de los límites de la nación, por lo que se recurre a eventos de la realidad social - como el accidente en la mina San José- que suscitan la unidad en torno a la nación chilena. Hemos constatado que la invisibilización en el discurso discriminatorio étnico-racial en la prensa escrita se presenta en dos procesos semióticos distintos e interrelacionados. En primera instancia, se aniquila y anula simbólicamente a la cultura mapuche en la "construcción" periodística que en-cubre la huelga de hambre de comuneros, mediante el amalgamiento de un mensaje icónico-verbal que los otrifica por medio del uso de lenguaje etnocéntrico para la nominalización de los aborígenes; escaso tratamiento periodístico relativo al movimiento reivindicativo; silenciamiento de la voz mapuche en el uso de la intertextualidad; escasa saliencia tanto de los 
mapuche en las fotografías como de la noticia étnica en cuestión, dados la poca centralidad y tamaños de las mismas. Invisibilización discursiva que calificamos de "flagrante", "directa" y que — siguiendo a Bañón Hernández (1996) - hace ver que la marginación o los marginados no existen. Estrategias semio-discursivas presentes en el lenguaje y en la imagen del trabajo periodístico del Diario La Cuarta y en la fotografía de los textos noticiosos de El Mercurio. Por el contrario, se intenta edulcorar esta anulación simbólica de la cultura mapuche a nivel lingüístico en la cobertura noticia del diario El Mercurio por la vía del uso de un lenguaje "políticamente correcto", menos frontal, más sutil, pero no por ello menos discriminador. En segunda instancia, existe aniquilamiento y anulación de la cultura mapuche en la hiper-cobertura noticiosa que se le otorgó al rescate de los mineros. Prueba de ello es que - a pesar que los dos eventos noticiosos (la huelga mapuche y el rescate minero) se desarrollan coetáneamente - en gran medida, la prensa estudiada provee una atención periodística casi exclusiva al accidente en la mina San José, en perjuicio del movimiento mapuche. Dicha invisibilización étnica como práctica social es producto de condicionantes sociohistóricas y sociocognitivas que sostienen y explican las relaciones sociales de exclusión/inclusión y dominación/subordinación y de rutinas profesionales racistas que moldean las temáticas de la multiculturalidad en la prensa escrita chilena.

\section{REFERENCIAS BIBILOGRÁFICAS}

ASTURIANO, P. (2005). “`JJau, rosto pálido!’. Análisis sociolingüístico del discurso etno-racial en el western". Revista Tono Digital 10, noviembre, s. p. http://www.um.es/tonosdigital/znum10/secciones/ Jau.pdf [10/01/2015].

BORRAT, H. (1989). El periódico, actor político. Barcelona: Gustavo Gili. 
DIJK, T.A. van (1996). “Análisis del discurso ideológico”, trad. Ramón Alvarado. Versión 6, 15-43.

(1999). “¿Un estudio lingüístico de la ideología?”. En Discurso, Cognición y Educación. Ensayos en Honor a Luis A. Gómez Macker, Parodi (ed.), 27-42. Valparaíso: Ediciones Universitarias de la Universidad Católica de Valparaíso.

(2006). "Discurso de las élites y racismo institucional". En Medios de comunicación e inmigración, M. Lario (ed.), 15-34. Murcia: CAM.

FAIRCLOUGH, N. (1992). Discourse and Social Change. Oxford: Blackwell.

FONTCUBERTA, M. de y VELÁZQUEZ, T. (1987). "La interpretación de la noticia periodística". En Métodos de análisis de la prensa. Encuentros sobre metodología del análisis de la Prensa (en torno a EL PAIS). Rencontre organisée par la Casa de Velázquez, Madrid, 7 et 8 février, 1985, G. Imbert (ed.), 91-111. Madrid. Casa de Velázquez.

FOUCAULT, M. (1991). Microfisica del poder. Madrid: Las Ediciones de la Piqueta.

GREIMAS, A. y COURTÉS, J. (1982). Diccionario razonado de la teoría del lenguaje. Madrid: Gredos.

HERNÁNDEZ, B. (1996). Racismo, discurso periodístico y didáctica de la lengua. Almería: Universidad de Almería.

KRESS, G y VAN LEEUWEN, T. (1996). Reading images. Londres: Routledge.

MARTÍNEZ, M. (2006). "Una aproximación a la imagen del inmigrante en los textos multimodales de la prensa alicantina. ¿Estereotipos o realidad?”. En Otras miradas sobre la inmigración, C. Gómez Gil (ed.), 151-174. Alicante: Universidad de Alicante.

MELLA, E. (2007). Los Mapuches ante la justicia: la criminalización de la protesta indigena en Chile. Santiago de Chile: LOM Ediciones.

PUYOL, F. (2010). El rescate de los 33 mineros: una epopeya coral. Análisis de impacto mediático y de reputación. Pamplona: 
Universidad de Navarra.

SAEZ, J. (2015). “Análisis crítico del discurso y representación de los mapuches en la prensa escrita chilena". Lenguas y Literaturas Indoamericanas 17, 145-169.

TAGUIEFF, P. (2010). "Introducción" El color y la sangre. Doctrinas a racistas a la francesa. Estudiar el racismo, textos y herramientas Antologíadetextosteóricos traducidosalespañolreferidosalestudio del racismo. Documento de Trabajo AFRODESC / EURESCL, n. ${ }^{\circ}$ 8. O. Hoffmann y O. Quintero (eds.), 21-35. Disponible en HAL: https://halshs.archives-ouvertes.fr/halshs-00691352/document [31/08/2018].

VÁZQUEZ MEDEL, M. (1998). "La prensa escrita y la construcción social de la realidad". En La democratización de los medios. Radiotelevisión comunitaria. Segundo Congreso de Radio y Tv locales públicas y alternativas, M. Chaparro (ed.), 123-145. Sevilla: EMA-RTV.

VELÁZQUEZ, T. (2011). "Las técnicas del análisis socio-semiótico”. En La investigación en comunicación. Métodos y técnicas en la era digital, L. Vilches (coord.), 237-264. Barcelona: Gedisa.

VON FOERSTER, H. (1994). “Construyendo una realidad” En La realidad inventada, P. Watzlawick, P. (comp.), 38-56. Barcelona: Gedisa.

WATZLAWICK, P. (comp.) (1994). La realidad inventada. Barcelona: Gedisa.

Recibido el 29 de abril de 2018.

Aceptado el 4 de septiembre de 2018. 
